\title{
Two special indications for intraocular lens implantation
}

\author{
B. BIEDNER, L. ROTHKOFF, * T. MONOS, AND M. BLUMENTHAL* \\ From the Department of Ophthalmology, Soroka Medical Centre, Beersheba, Israel
}

SUMMARY Two cases with special indications for intraocular lens implants are presented. The first case was of a 60 -year-old monocular patient with congenital absence of the external nose and multiple limb deformities. The second case was of a young Bedouin girl with bilateral developmental cataracts who had poor living conditions and social objections to wearing spectacles. Intraocular lenses restored good vision.

The indications for the insertion of intraocular lenses are still controversial. Guidelines have been published (Jaffe, 1976) which advise restriction of pseudophakai to the elderly patient with monocular cataract who will not tolerate a contact lens. We wish to present 2 patients who we feel exemplify 2 special indications for intraocular lens implantation.

\section{Case reports}

CASE 1

A 60-year-old woman presented for cataract extraction in her left eye. She was known to have a congenital absence of the external nose (Fig. 1). Her right eye was phthisical after a childhood injury. The left eye had a visual acuity of hand movements only, with good light projection, 2-point discrimination, and colour perception. The lens was almost mature and prevented visualisation of the retina. A-scan ultrasound was normal. The patient also had a severe kyphoscoliosis and malformations of her extremities. She had previously been told by her physicians that, since she could wear spectacles only with difficulty, cataract removal was not indicated until she was totally blind.

Because of the multiple handicap and the absence of the external nose needed to support the heavy aphakic glasses we considered that an intraocular lens implant was indicated. On 2 May 1976 under local anaesthesia the patient underwent an uncomplicated, extracapsular cataract extraction with implantation of a Binkhorst iridocapsular lens. The postoperative course was uneventful. When she

*Present address: Eye Institute, Chaim Sheba Medical Centre, Tel Hashomer, Israel

Address for reprints: Dr B. Biedner, Soroka Medical Centre, Beersheba, Israel

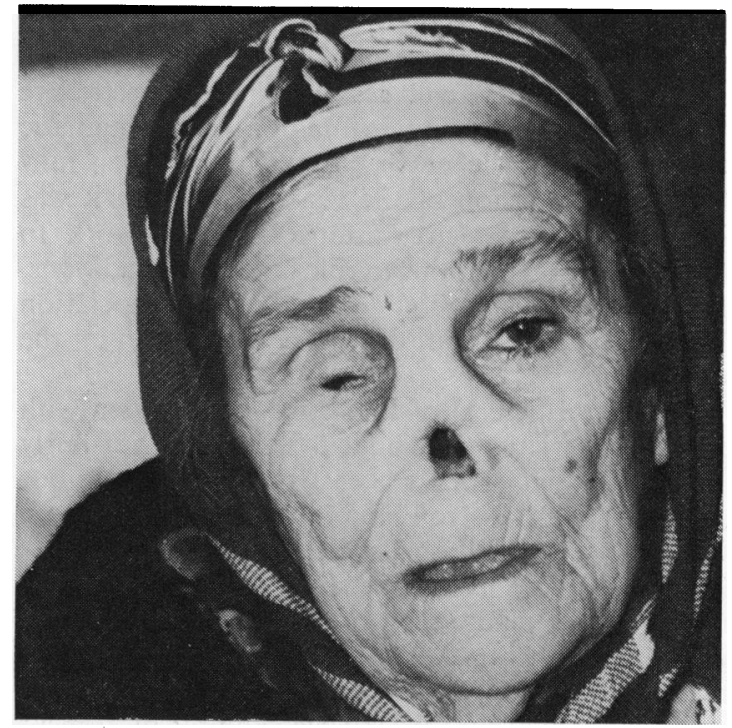

Fig. 1 Case 1. Congenital absence of external nose

was last seen on 23 August 1977 her uncorrected visual acuity was $6 / 18$, which could be corrected to $6 / 12$ with a small astigmatic correction. The patient is happy with her uncorrected vision and being illiterate is not hampered by her poor near vision.

CASE 2

A 20-year-old Bedouin girl was known to have progressive, developmental cataracts. No cause could be determined, and no other abnormalities were present. On admission vision was finger counting at $0.5 \mathrm{~m}$ in the right eye and $6 / 12$ in the left eye. There was an almost mature cataract in the right eye, while the left eye had posterior subcapsular and nuclear changes. Bedouin women 
will not wear eyeglasses, even after cataract extraction, because of the severe social stigma. Contact lenses could not be considered because of poor living conditions. It was therefore decided to implant an intraocular lens.

On 14 February 1975 the patient underwent an uncomplicated, extracapsular cataract extraction in her right eye with implantation of a Binkhorst iridocapsular lens. The postoperative course was uneventful, and her uncorrected vision 10 weeks postoperatively was 6/9. By this time vision in her left eye had decreased to finger counting only, and an uncomplicated, extracapsular cataract extraction was performed with implantation of a Binkhorst iridocapsular intraocular lens. The postoperative course was uneventful, and when she was last seen on 27 March 1977 her visual acuity uncorrected in the right eye was $6 / 9$ and in the left eye $6 / 12$. The patient had been happily married in the interval.

\section{Discussion}

Though we generally restrict our intraocular lens implants to elderly patients with monocular cataract, we considered that these 2 cases justified flexibility of these guidelines for social and physical reasons. Our first case, with absence of the external nose and malformation of the extremities, could not be expected to wear a contact lens or spectacles for purely physical reasons. The young Bedouin girl with bilateral cataracts could not be corrected with contact lenses because her living conditions precluded this, and she would not wear spectacles because of sociocultural reasons. In both cases successful intraocular lens implantation restored near normal vision, which otherwise could not have been obtained. We believe both these patients are representative of a special group of cataract patients who before the advent of intraocular lens implants could not be adequately rehabilitated but are now most benefited by this new technique.

\section{Reference}

Jaffe, N. S. (1976). Suggested guidelines for intraocular lens implant surgery. Archives of Ophthalmology, 94, 214-216. 